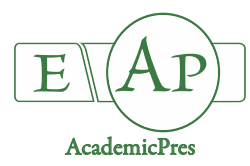

\title{
Sexual and Vegetative Propagation of Hypericum empetrifolium Willd. subsp. empetrifolium
}

\section{Anastasia AKOUMIANAKI-IOANNIDOU ${ }^{1 *}$, Ekaterini GERASIMIDOU ${ }^{1}$, Alexandra SALTA ${ }^{1}$, Ioannis ROUSSIS ${ }^{2}$, Dimitrios BILALIS ${ }^{2}$}

\author{
${ }^{1}$ Agricultural University of Athens, Department of Crop Science, Laboratory of Floriculture and Landscape Architecture, 75 Iera Odos Str., 118 \\ 55Athens, Greece; akouman@aua.gr (*orrespondingauthor); katerina.gerasimidou@gmail.com; alexandrasalta@yahoo.gr \\ ${ }^{2}$ Agricultural University of Athens, Department of Crop Science, Laboratory of Agronomy, 75 Iera Odos Str., 11855 Athens,
}

Greece;iroussis01@gmail.com; bilalisdimitrios@gmail.com

\begin{abstract}
Hypericum empetrifolium Willd. subsp. empetrifolium is an evergreen small shrub with small elongated decorative leaves and small yellow flowers in inflorescences, characterized for several pharmaceutical properties. In the present study, a first approach on the sexual and asexual propagation of this species was performed. Seeds, subjected to different types of pretreatments [soaked in tap water; 50,100 or $150 \mathrm{mg} \mathrm{L}^{-1} \mathrm{GA}_{3}$ for $30 \mathrm{~min}$ and no treatment (control)], cultured for germination in petri dishes at $5,10,15,20,25$, and $30^{\circ} \mathrm{C}$. Seed germination was only affected by temperature and the best result was obtained at $15^{\circ} \mathrm{C}(71.2 \%)$. A significant interaction was found between pre-treatments and incubation temperature with the highest germination percentage (82\%) occurred when the seeds soaked in $100 \mathrm{mg} \mathrm{L}^{-1} \mathrm{GA}_{3}$ solution for 30 min and incubated at $20^{\circ} \mathrm{C}$ constant temperature. Moreover, the germination speed was fastest from 20 to $25^{\circ} \mathrm{C}\left(\mathrm{T}_{50}=9.84\right.$ and 9.56 days for 20 and $25^{\circ} \mathrm{C}$, respectively). For asexual propagation, apical stem cuttings were taken at four different periods ( 4 seasons) and treated with IBA at concentrations of $0,1000,2000$ and $3000 \mathrm{mg} \mathrm{L}^{-1}$. The cuttings were planted in a peat/perlite mixture 1:1 $\mathrm{v} / \mathrm{v}$ in plastic square plug trays in order to study the rooting percentage. Winter was the most appropriate season for cuttings collection (100\% rooting percentage) and dipping in 1000 or $2000 \mathrm{mg} \mathrm{L}^{-1}$ IBA ( $72 \%$ and $73 \%$, respectively) was the best rooting hormone treatment.
\end{abstract}

Keywords: indole-3-butyric acid (IBA); medicinal plant; ornamental value; seed germination; stem cutting

\section{Introduction}

Hypericum empetrifolium Willd. subsp. empetrifolium (Hypericaceae) is a small evergreen shrub, widespread at low altitudes in the Aegean area, the south part of the Greek mainland and the coastal area of western Turkey (Trovato et al., 2001). Its stem is up to $50 \mathrm{~cm}$ tall, erect or prostrate with strict branching from the base. Leaves are $2-12 \mathrm{~mm}$, short, narrow, needle-like in whorls of three and hairless. Deep yellow flowers are numerous and densely black-dotted in elongated panicles or simple cymes that form from April to June. The fruit is an ovate capsule with oblique vesicles (Davis, 1988). In Greece, H. empetrifolium subsp. empetrifolium is traditionally used as a medicinal plant with high antioxidant and antibacterial activity, while decoctions of the flowers are taken internally as an anthelmintic and diuretic and used externally as a wash to speed healing of wounds, scalds, and herpes (Petrakis et al., 2005). Several phytochemical investigations on this species have been described the presence of naphthodianthrones and flavonoids in crude extracts of the flowers (Kitanov, 2001) as well as the composition of the essential oil (Petrakis et al., 2005).

Apart from medicinal value, $H$. empetrifolium subsp. empetrifolium has potential value use as a landscape plant because of its yellow and black-dotted flowers forming a nice contrast to the dark green foliage. In addition, this plant does not lose its leaves in the winter and retains this wonderful ornamental value even in the cold season. This plant species could be used in Mediterranean parks, gardens and archaeological sites contributing to the biodiversity enrichment and reflecting the traditional character of the area (Diekelmann and Schuster, 2002; Papafotiou et al., 2017).

Seed germination consists a critical stage of the plant life cycle and usually controls the plant population dynamics 
with significant practical consequences (Çirak, 2007). In spermatophytes, it is a complex trait which is influenced by many genes and environmental factors (Carta et al., 2016). The seeds of 59 Hypericum species have been recorded as orthodox, indicating that the life cycle of these species in the field may be related with deep seed dormancy (SánchezCoronado et al., 2015). Indeed, it has been found that the germination capacity of Hypericum species is very low mainly due to the prolonged seed dormancy (Carta et al., 2016). The low seed germination in $H$. perforatum (Campbell, 1985) and $H$. aviculariifolium (Cirak et al., 2007) is caused by a chemical inhibitor in the capsule. Plant growth regulators such as $\mathrm{GA}_{3}$ (gibberellic acid) and IAA (indole-3-acetic acid) have been recommended to break seed dormancy and enhance seed germination (Çirak, 2007). Cirak et al. (2011) found that $\mathrm{GA}_{3}$ increased germination rate of $H$. triquetrifolium significantly as compared to control; $68 \%$ germination for seed treated with $100 \mathrm{mg} \mathrm{L} \mathrm{maA}_{3}$ compared to approximately $30 \%$ for untreated seeds. Other factors, reported to affect the seed germination of several Hypericum species, are light and fluctuating temperatures which are common requirements for small-sized seeds (Thompson et al., 2001). Carta et al. (2016) found the optimum temperatures for germination of $\mathrm{H}$. elodes to be alternating $30 / 20^{\circ} \mathrm{C}$ with a 12 -h daily photoperiod, whereas Bertelle et al. (2004) suggested that a temperature of $20{ }^{\circ} \mathrm{C}$ and $30{ }^{\circ} \mathrm{C}$ is the recommended for germination in $H$. perforatum and $H$. brasiliense seeds, respectively.

The vegetative or asexual propagation by stem cuttings is a simple and easily applied method of propagation, while it offers productions of true-to-type plants in a short time period and availability of superior individuals for large scale commercial plantation with quick productive gains (Shekhawat and Manokari, 2016). However, for each plant species, it is necessary to know the appropriate concentration of the rooting hormone and cutting collection period. Auxins are commonly used in cutting propagation as root-promoting chemicals ( $\mathrm{Lu}$ et al., 2008). Nevertheless, it has to be noted that, the effect of exogenous application of auxins may vary from ineffective to promotive, or even inhibitory for the rooting of cuttings, depending on the endogenous level of growth-regulating substances or the tissue sensitivity (AkoumianakiIoannidou et al., 2016). This results in the definition of the optimal concentrations of auxins for the rooting of each species. Regarding the time of cuttings collections, it plays an important role in rooting success and development of cuttings, because of the changes in the endogenous plant growth regulators or carbohydrate conditions of cuttings as well as the conditions in the nursery growing environment (Klein et al., 2000).

A survey of the literature revealed than no study on sexual or asexual propagation of $H$. empetrifolium subsp. empetrifolium has been undertaken. The purpose of this study was to investigate seed germination and asexual propagation of this species, in order to use as an ornamental plant in urban and suburban areas as well as a medicinal plant with potential usage in the pharmaceutical industry.

\section{Materials and Methods}

Experiment 1: Seed germination of $H$. empetrifolium subsp. empetrifolium

Dried seeds of $H$. empetrifolium subsp. empetrifolium were collected in August 2015 from selected mature plants in the region of 'Panagia Orphani' $\left(36^{\circ} 15^{\prime} 21.8^{\prime \prime} \mathrm{N}\right.$, $22^{\circ} 55^{\prime} 45.4^{\prime \prime} \mathrm{E}$, altitude $102 \mathrm{~m}$ ) in Kythira island, Greece and were stored in plastic bags at room temperature conditions (about $21{ }^{\circ} \mathrm{C}$ ) under darkness. A germination experiment was carried out twice; in June and August 2016. Seeds were surface sterilized by soaking in $15 \%$ chlorine dioxide solution for $10 \mathrm{~min}$ and then rinsed for $20 \mathrm{~min}$ with distilled deionized water. After the rinsing, seeds received various pre-treatments [soaked in tap water; 50,100 or 150 $\mathrm{mg} \mathrm{L}^{-1} \mathrm{GA}_{3}$ for $30 \mathrm{~min}$ and no treatment (control)] and then they were placed in $100 \times 15 \mathrm{~mm}$ petri dishes, on two sheets of filter paper moistened with $3 \mathrm{ml}$ distilled water at six constant temperatures $\left(5,10,15,20,25\right.$ and $\left.30{ }^{\circ} \mathrm{C}\right)$. Incubation of seeds took place with a 16-h light/ 8-h dark photoperiod. Cool white fluorescent tubes provided lighting with an irradiance of $37.5 \mu \mathrm{mol} \mathrm{m} \mathrm{m}^{-2} \mathrm{~s}^{-1}$. Each petri dish contained 10 seeds and represented one replication or experimental unit. Five replications per temperature and treatment were used. Germination percentages were evaluated every 2 days for 36 days and a seed was considered germinated when the radicle was longer than $1 \mathrm{~mm}$. $\mathrm{T}_{50}$ was also calculated according to Coolbear et al. (1980). The $\mathrm{T}_{50}$ was not estimated when the final germination percentage was $<5 \%$.

Experiment 2: Vegetative propagation of H. empetrifolium subsp. empetrifolium

Regarding asexual propagation, apical stem cuttings, 8$10 \mathrm{~cm}$ long, were excised from a population of native adult plants grown in the region of 'Diomedes Botanic Garden' $\left(38^{\circ} 00^{\prime} 39.2^{\prime \prime} \mathrm{N}, 23^{\circ} 38^{\prime} 11.32^{\prime \prime} \mathrm{E}\right.$, altitude $\left.157 \mathrm{~m}\right)$ in Haidari, a western suburb of Athens, Greece, in February, April, August and October indicative of the seasons spring, summer and autumn and winter, respectively. Two experiments were conducted during 2016 and 2017, but due to the similarity of the results, only data of one year are presented. In winter, stem cuttings were collected from the new growth of the plant, which was started to sprout. During the spring and summer, cuttings were excised from non-flowering shoots. The stem cuttings collected in autumn were more lignified due to the stop of shoot growth. All leaves and axillary shoots were removed from the basal half of the stem cuttings. The bases of the stem cuttings (around $1.5 \mathrm{~cm}$ of the bottom) were immersed in IBA ethanol-water (1:1, v/v) solutions, at different concentrations: 0 (control), 1000, 2000 and $3000 \mathrm{mg} \mathrm{L}^{-1}$, for $1 \mathrm{~min}$, and then placed for rooting in plastic square plug trays (cell dimensions: $5.0 \times 5.0 \times 5.0 \mathrm{~cm}$ ) containing a substrate of peat and perlite $(1: 1, \mathrm{v} / \mathrm{v})$ in a mist system $(15 \mathrm{~s}$ spraying every $15 \mathrm{~min}$ from May to September or every 30 min from October to April; substrate temperature $22{ }^{\circ} \mathrm{C}$ maintained by thermostatically controlled electric heating cable) for eight weeks. Three replications with ten cuttings were used in each treatment. 
284

Rooting percentages were determined every two weeks by checking cutting resistance in pulling and root emergence through the hole at the bottom of each planting cell.

\section{Statistical analysis}

For the statistical analysis, JMP 8 statistical software (SAS Institute Inc., Cary, USA) was used. All the experiments were conducted according to completely randomized design (CRD). The significance of the results was tested by one or two-way ANOVA and differences between means were separated using the LSD test. All comparisons were made at the $5 \%$ level of significance $(\mathrm{p} \leq$ $0.05)$. Finally, the data on percentage were statistically analyzed after arcsine transformation.

\section{Results and Discussion}

Experiment 1: Seed germination of $H$. empetrifolium subsp. empetrifolium

The effect of pre-treatments on seed germination was found not to be statistically significant (Table 1). However, $\mathrm{GA}_{3}$ (regardless of the concentration) increased the percentage of germinated seeds in comparison with the controls and the "tap water-treated" seeds at $10^{\circ} \mathrm{C}$.
Maintenance of dormancy is a consequence of high abscisic acid (ABA) content in mature seed and dormancy release has a strongly correlation with the reduction of $\mathrm{ABA}$ content. Gibberellins reduce the effects of $\mathrm{ABA}$ and overcome several types of seed dormancy, including physiological dormancy, photodormancy and thermodormancy acting as a substitute for low temperatures, long days or red light, respectively (Salisbury and Ross, 1992). The application of gibberellic acid $\left(\mathrm{GA}_{3}\right)$ to plants is known to modify the effect of cytokinins on transport across membranes and is thus able to initiate the biochemical processes necessary for seed germination. The cytokinin possibly penetrates the testa and neutralizes the inhibitors present in the embryo, enabling the embryo to rupture the seed coats (Chen et al., 2008). In general, the application of $\mathrm{GA}_{3}$ promotes germination of several Hypericum species such as $H$. perfoliatum and $H$. pruinatum indicating the presence of physiological dormancy related to partially dormant embryo (Cịrak et al., 2007).

The temperature at which seeds were incubated after pre-soaking treatments significantly affected final germination percentages (Table 1). The optimum temperature for seed germination was $15^{\circ} \mathrm{C}$ at which the maximum germination percentage (76\%) was achieved without any pretreatment indicating that there was no dormancy in seeds after their storage for 10-12 months.

Table 1. The effect of pre-treatments and temperature on seed germination and germination speed $\left(\mathrm{T}_{50}\right)$ of Hypericum empetrifolium subsp. empetrifolium

\begin{tabular}{|c|c|c|c|}
\hline Treatment & Temperature $\left({ }^{\circ} \mathrm{C}\right)$ & Germination $(\%) \pm S E$ & $\mathrm{~T}_{50}$ \\
\hline \multirow[t]{6}{*}{ Untreated (Control) } & 5 & $0.0 \pm 0.0$ & - \\
\hline & 10 & $20.0 \pm 8.4$ & 26.8 \\
\hline & 15 & $76.0 \pm 5.1$ & 15.1 \\
\hline & 20 & $62.0 \pm 9.7$ & 9.6 \\
\hline & 25 & $34.0 \pm 4.0$ & 12.0 \\
\hline & 30 & $0.0 \pm 0.0$ & - \\
\hline \multirow[t]{6}{*}{ Tap Water } & 5 & $0.0 \pm 0.0$ & - \\
\hline & 10 & $14.0 \pm 7.4$ & 23.5 \\
\hline & 15 & $70.0 \pm 5.5$ & 15.4 \\
\hline & 20 & $80.0 \pm 7.1$ & 9.6 \\
\hline & 25 & $28.0 \pm 7.3$ & 11.2 \\
\hline & 30 & $0.0 \pm 0.0$ & - \\
\hline \multirow[t]{6}{*}{$\mathrm{GA}_{3} 50 \mathrm{mg} \mathrm{L}^{-1}$} & 5 & $0.0 \pm 0.0$ & - \\
\hline & 10 & $46.0 \pm 12.9$ & 23.3 \\
\hline & 15 & $72.0 \pm 4.9$ & 14.4 \\
\hline & 20 & $64.0 \pm 5.1$ & 9.6 \\
\hline & 25 & $36.0 \pm 8.1$ & 8.4 \\
\hline & 30 & $4.0 \pm 4.0$ & - \\
\hline \multirow[t]{6}{*}{$\mathrm{GA}_{3} 100 \mathrm{mg} \mathrm{L}^{-1}$} & 5 & $0.0 \pm 0.0$ & - \\
\hline & 10 & $40.0 \pm 7.1$ & 23.2 \\
\hline & 15 & $66.0 \pm 2.4$ & 13.8 \\
\hline & 20 & $82.0 \pm 5.8$ & 9.4 \\
\hline & 25 & $44.0 \pm 10.3$ & 9.2 \\
\hline & 30 & $0.0 \pm 0.0$ & - \\
\hline \multirow[t]{6}{*}{$\mathrm{GA}_{3} 150 \mathrm{mg} \mathrm{L}^{-1}$} & 5 & $0.0 \pm 0.0$ & - \\
\hline & 10 & $50.0 \pm 12.2$ & 23.4 \\
\hline & 15 & $72.0 \pm 3.7$ & 15.0 \\
\hline & 20 & $68.0 \pm 8.6$ & 9.6 \\
\hline & 25 & $30.0 \pm 5.5$ & 8.4 \\
\hline & 30 & $0.0 \pm 0.0$ & - \\
\hline$F_{\text {pre-treatment }}$ & & ns & ${ }^{*}\left(\mathrm{LSD}_{5 \%}=1.026\right)$ \\
\hline$F_{\text {temperature }}$ & & ${ }^{* * *}\left(\operatorname{LSD}_{5 \%}=4.264\right)$ & ${ }^{* * *}\left(\operatorname{LSD}_{5 \%}=4.019\right)$ \\
\hline$F_{\text {pre-treatment } X \text { temperature }}$ & & ${ }^{* *}\left(\mathrm{LSD}_{5 \%}=17.396\right)$ & ns \\
\hline
\end{tabular}

F-test ratios are from ANOVA. Significant at ${ }^{*},{ }^{* *}$ and ${ }^{* * *}$ indicate significance at $\mathrm{p} \leq 0.05,0.01$ and 0.001 , respectively and ns: not significant. The $L S D$ test (p $\leq 0.05$ ) values for pre-treatment and temperature are also presented. SE: Standard Error. 
In other species of genus Hypericum, namely $H$. orientale, $H$. perfoliatum, $H$. pruinatum, $H$. origanifolium, $H$. triquetrifoliuum, $H$. heterophyllum, the recommended temperature for seed germination was set at $20{ }^{\circ} \mathrm{C}$ (Çirak, 2007; Çirak et al., 2011).

In a previous study, it was found that germination of Hypericum elodes was greatly promoted in seeds subjected to diurnal alternating temperatures of $20 / 10$ and $25 / 15^{\circ} \mathrm{C}$ (Carta et al., 2016). However, all these researchers suggested cold stratification at $5{ }^{\circ} \mathrm{C}$ cold for 12 weeks, and/ or light and exogenously applied $\mathrm{GA}_{3}, \mathrm{KNO}_{3}$, hot water and tap water for breaking the seed dormancy of aforesaid Hypericum species (Çirak, 2007; Çirak et al., 2011; Carta et al., 2016).

According to Carta et al. (2016), the environment during seed maturation affects dormancy degree in Hypericum species. Several environmental factors, including light, moisture, temperature and nutrients, as well as the age of the mother plant during seed growth and maturation and the position of the seeds on the plant can lead to variations in germination behaviour among seeds of a species (Gutterman, 2000).

A significant interaction was found between pre-soaking treatments and incubation temperature. The highest germination percentage $(82 \%)$ occurred when the seeds soaked in $100 \mathrm{mg} \mathrm{L}^{-1} \mathrm{GA}_{3}$ solution for $30 \mathrm{~min}$ and incubated at $20^{\circ} \mathrm{C}$ constant temperature. This observation indicates that $\mathrm{GA}_{3}$ can be used for the breakage of seed dormancy at supra-optimal high temperatures, as has been shown in lettuce (Dong et al., 2012).

The incubation temperature significantly affected the germination rate, as expressed by $\mathrm{T}_{50}$ values. Generally, the germination speed $\left(T_{50}\right)$ was enhanced by the increase of temperature. It was not possible to calculate $\mathrm{T}_{50}$ for $5{ }^{\circ} \mathrm{C}$ and $30^{\circ} \mathrm{C}$ due to the low final germination $(<5 \%)$ at these temperatures. The germination speed for the range of the tested constant temperatures allowed an optimal range to be identified from 20 to $25^{\circ} \mathrm{C}\left(9.84\right.$ and 9.56 for 20 and $25^{\circ} \mathrm{C}$, respectively). Poor germination at very low and high temperatures in legume species such as Vigna unguiculata may indicate that little or no germination will take place during winter or mid-summer and could act as a protection mechanism against excessive seedling mortality (Balkaya, 2004). Regarding the effect of pre-soaking treatments on germination speed, the results of this experiment demonstrated that exogenously applied $\mathrm{GA}_{3}$ at $100 \mathrm{mg} \mathrm{L}^{-1}$ shows promise as a practical method of improving the germination percentage, rate, and uniformity of $H$. empetrifolium subsp. empetrifolium.

\section{Experiment 2: Vegetative propagation of H. empetrifolium subsp. empetrifolium}

Root initiation and development in stem cuttings is controlled by a complex of ecophysiological and biochemical processes and morphological factors, as well (Uniyal et al., 1993). There is an overpowering evidence that auxins have been shown to improve overall rooting percentages, hasten root initiation and increase the number and quality of roots, which can be either naturally occurring within the plant (endogenous) or applied to the plant (exogenous) throughout vegetative propagation (Blythe $e t$ al., 2007; Hartmann et al., 2011). Synthetic auxins such as indole-3-butyric acid (IBA) and 1-naphthaleneacetic acid (NAA) are commonly used to promote root development in the vegetative propagation. Auxins promote the starch hydrolysis as well as the mobilization of sugars and nutrients at the base of the cuttings during the regeneration of adventitious roots (Nanda et al., 1974). The rooting success depends upon the proper balance between nutrient and auxin levels in cuttings.

According to the analysis of variance, the different IBA concentrations had also significant effect $(\mathrm{F}=3.356, \mathrm{p}=$ $0.024)$ on rooting. The higher average rooting percentages were achieved at 1000 and $2000 \mathrm{mg} \mathrm{L}^{-1} \mathrm{IBA}$ (72\% and $73 \%$, respectively; Fig. 1). The untreated stem cuttings had shown the least rooting performance (60\%). Thetford and Miller (2002) conducted an experiment to investigate the influence of IBA and NAA on rooting of stem cuttings of Hypericum reducium and found that cuttings can root in high percentages up to $70 \%$ even without the use of exogenous auxins. The application of auxin is known to intensify root-forming process in stem cuttings. Usually polysaccharide hydrolysis is activated under the effect of applied IBA, and as a result, the content of physiologically active sugar increased providing materials and energy for meristematic tissues and later for root primordia and roots (Leakey et al., 1982).

Although auxins have been found to catalyze enzymatic reactions and thus increase the rate and quality of root production, in high concentrations they can have the opposite effect and retard or inhibit the formation of roots (Puri and Verma, 1996). In general, the use of auxins stimulates rooting of different propagating materials, but the concentration to be used for this purpose varies with the species, the maturity level of the propagating material, the environment as well as the mode of application of the plant growth regulators to the plants (Leakey et al., 1982; Akoumianaki-Ioannidou et al., 2016).

Rooting of the stem cuttings was also significantly affected by the collection season $(\mathrm{F}=66.203, \mathrm{p}<0.001$; Fig. 2 ) and is attributable to morphological and physiological characteristics of the stock plant at time of cutting collection (Hartmann et al., 2011). Highest rooting rates were achieved in winter $(100 \%)$ in all treatments regardless of IBA application. In autumn, the average rate of rooting percentage was $77.5 \%$ with significant difference compared to the winter. In summer, rooting was relatively limited (61\%) and in spring much lower (28\%). The superiority of winter may be related to the fact that cuttings of several species taken in February contain higher level of sugars and total carbohydrate content and have higher eroxidase enzyme activity, which are found to have positive relationships with rooting response (Veierskov et al., 1982; Bhardwaj and Mishra, 2005). Moreover, the new vegetation of H. empetrifolium subsp. empetrifolium, which sprouts in the late of the winter, has as a result, the cuttings collected during this period, may be richer in endogenous auxins produced at the active apex of the young shoot, and transported basipetally to the cut surface in sufficient amounts to act as trigger (Nordström and Eliasson, 1991). 


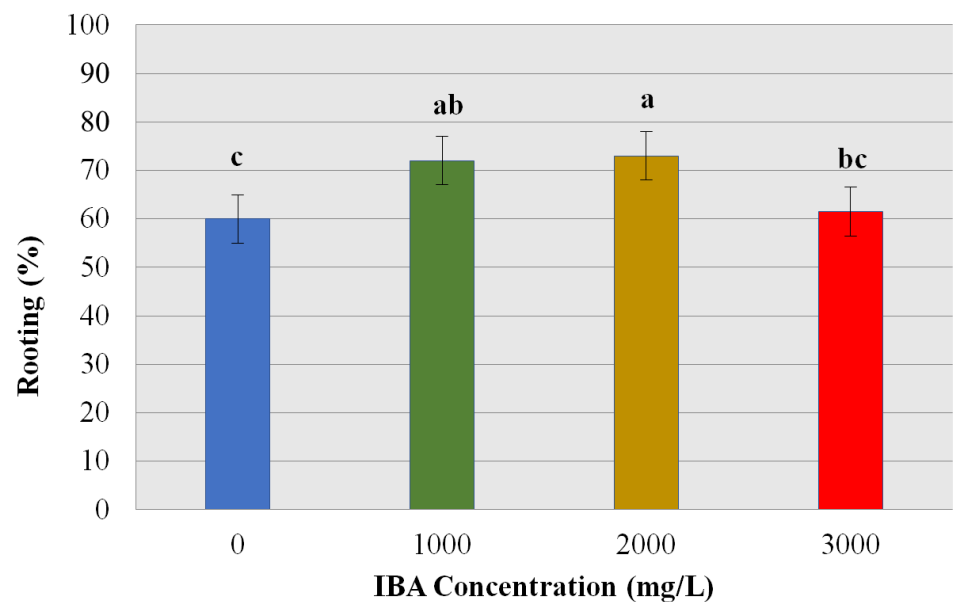

Fig. 1. The effect of IBA concentration on rooting percentage of Hypericum empetrifolium subsp. empetrifolium stem cuttings, regardless of season collection. Vertical bars and different lower-case letters denote standard errors of the means and statistically significant differences $(\mathrm{p} \leq 0.05)$, respectively

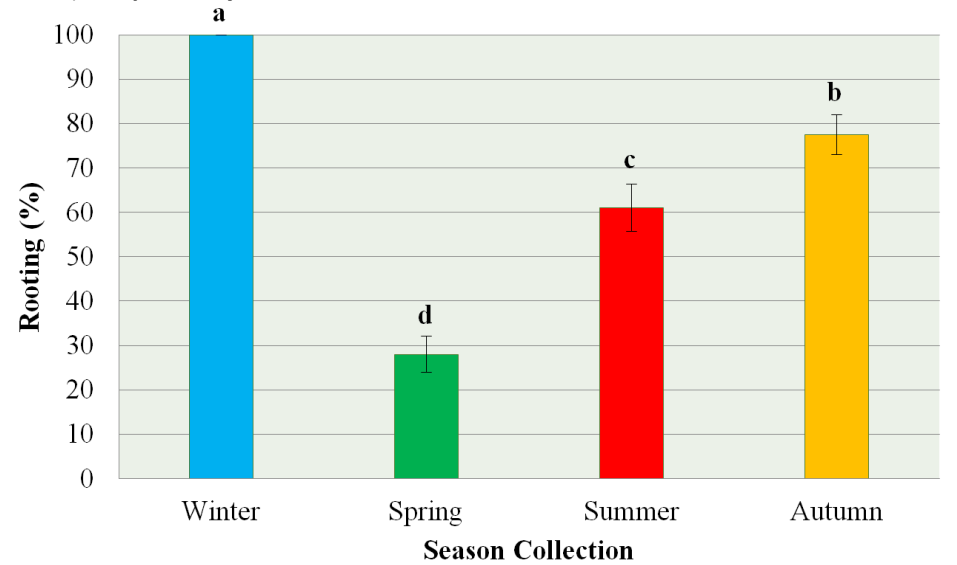

Fig. 2. The effect of season collection on rooting percentage of Hypericum empetrifolium subsp. empetrifolium stem cuttings. Vertical bars and different lower-case letters denote standard errors of the means and statistically significant differences ( $\mathrm{p} \leq$ $0.05)$, respectively

Contrariwise, in the literature, it is referred that within the genus Hypericum, the late-summer softwood cuttings from tips of current growth can root easily (Thetford and Miller, 2002). Ambient temperature is rather unlikely affect rooting, as the temperature in the mist system was constant. Finally, in the vegetative propagation experiment, interaction between IBA and collection season was not found $(\mathrm{F}=1.650, \mathrm{p}=0.120)$.

\section{Conclusions}

In conclusion, data of the present study indicated that the seeds of $H$. empetrifolium subsp. empetrifolium did not exhibit dormancy. However, exogenously applied $\mathrm{GA}_{3}$ at $100 \mathrm{mg} \mathrm{L}^{-1}$ can be used, as a practical method, to improve the germination percentage, rate, and uniformity of this species. Regarding vegetative propagation, rooting of stem cuttings was affected both by collection season and rooting hormone treatment. Winter was the most appropriate season for cuttings collection and dipping in 1000 or 2000 $\mathrm{mg} \mathrm{L}^{-1} \mathrm{IBA}$ was the best rooting hormone treatment. These results should provide a basis from which efforts may be made toward the advancement of vegetative propagation of H. empetrifolium subsp. empetrifolium by stem cuttings.

\section{References}

Akoumianaki-Ioannidou A, Martini AN, Papafotiou M (2016). Rooting and establishment of Limoniastrum monopetalum (L.) Boiss stem-tip cuttings. African Journal of Plant Science 10(1):23-31.

Balkaya A (2004). Modelling the effect of temperature on the germination speed in some legume crops.Journal of Agronomy 3(3):179-183.

Bertelle FML, Beatriz PM, Augusto LA (2004). Light, temperature and potassium nitrate in the germination of Hypericum perforatum $\mathrm{L}$. and $H$. brasiliense Choisyseeds. Bragantia 63:193-199.

Bhardwaj DR, Mishra VK (2005). Vegetative propagation of Ulmus villosa: Effects of plant growth regulators, collection time, type of donor and position of shoot on adventitious root formation in stem cuttings. New Forest 29:105-116. 
Blythe EK, Sibley JL, Tilt KM, Ruter JM (2007). Methods of auxin application in cutting propagation: A review of 70 years of scientific discovery and commercial practice. Journal of Environmental Horticulture 25:166-185.

Campbell MH (1985). Germination, emergence and seedling growth of Hypericum perforatum. Weed Research 25:259-266.

Carta A, Probert R, Puglia G, Peruzzi L, Bedini G (2016). Local climate explains degree of seed dormancy in Hypericum elodes $\mathrm{L}$. (Hypericaceae). Plant Biology 18(Suppl. 1):76-82.

Chen SY, Shing-Rong K, Ching-Te C (2008). Roles of gibberellins and abscisic acid in dormancy and germination of red bayberry (Myrica rubra) seeds. Tree Physiology28:1431-1439.

Çirac C (2007). Seed germination protocols for ex situ conservation of some Hypericum species from Turkey. American Journal of Plant Physiology 2(5):287-294.

Çrak C, Kevseroglu K, Ayan AK (2007). Breaking of seed dormancy in a Turkish endemic Hypericum species: Hypericum avicularïfolium subsp. depilatum var. depilatum by light and some pre-soaking treatments. Journal of Arid Environments 68:159-164.

Cịrak C, Radusiene J, Janulis V, Ivanauskas L, Camas N, Ayan AK (2011). Phenolic constituents of Hypericum triquetrifolium Turra (Guttiferae) growing in Turkey: variation among populations and plant parts. Turkish Journal of Biology 35:449-456.

Coolbear P, Grierson D, Heydecker W (1980). Osmotic pre-sowing treatments and nucleic acid accumulation in tomato seeds (Lycopersicon bcopersicum). Seed Science and Technology 8:289-303.

Davis PH (1988). Flora of Turkey and the East Aegean Islands, vol. 2. Edinburgh University Press, Edinburgh.

Dong T, Tong J, Xiao L, Cheng H, Song S (2012). Nitrate, abscisic acid and gibberellin interactions on the thermoinhibition of lettuce seed germination. Plant Growth Regulation 66:191-202.

Diekelmann J, Schuster R (2002). Natural landscaping. Designing with native plant communities. The University of Wisconsin Press ( $\left.2^{\text {nd }} \mathrm{ed}\right)$, Madison, WI.

Gutterman Y (2000). Maternal effects on seeds during development. In: Fenner M (Ed). Seeds: the ecology of regeneration in plant communities. Red-wood Press, Melksham, UKpp 59-84.

Hartmann HT, Kester DE, Davies FT Jr, Geneve RL (2011). Plant propagation: principles and practices. New York: Prentice-Hall ( $\left.8^{\text {th }} \mathrm{ed}\right)$, Sao Paulo.

Kitanov GM (2001). Hypericin and pseudohypericin in some Hypericum species. Biochemical Systematics and Ecology 29:171-178.

Klein JD, Cohen S, Hebbe Y (2000). Seasonal variation in rooting ability of myrtle (Myrtus communis L.) cuttings. Scientia Horticulturae 83(1):7176.

Leakey RRB, Chapman VR, Longman KA (1982). Physiological studies for tropical tree improvement and conservation. Some factors affecting root initiation in cuttings of Triplochiton scleroxylon K. Schum. Forest Ecology and Management 4(1):53-66.
Lu C-T, Sung J-M, Chen C-L (2008). 2,4Dichlorophenoxyacetic acid soaking promotes rooting in stem tip cuttings of Hypericum perforatum. Journal of Agriculture and Forest 57(3-4):99-110.

Nanda KK, Kumar P, Kochhar BK (1974). Role of auxins in influencing rooting of cuttings. New Zealand Journal of Forestry Science 4:338-346.

Nordström AC, Eliasson L (1991). Levels of endogenous indole-3-acetic acid and Indole-3-acetylaspartic acid during adventitious root formation in pea cuttings. Physiologia Plantarum 82(4):599-605.

Papafotiou M, Bertsouklis KF, Martini AN, Vlachou G, AkoumianakiIoannidou A, Kanellou E, Kartsonas ED (2017). Evaluation of the establishment of native Mediterranean plant species suggested for landscape enhancement in archaeological sites of Greece. Acta Horticulturae 1189:177-180.

Petrakis P, Couladis M, Roussis V (2005). A method for detecting the biosystematic significance of the essential oil composition: The case of five Hellenic Hypericum L. species. Biochemical Systematics and Ecology 33:873-898.

Puri S, Verma RC (1996). Vegetative propagation on Dalbergia sisoo Roxb. using softwood and hardwood stem cuttings. Journal of Arid Environments 34(2):235-245.

Salisbury FB, Ross CW (1992). Plant Physiology. Wadsworth Publishing Company ( $4^{\text {th }}$ ed), Belmont.

Sánchez-Coronado ME, Olvera C, Márquez-Guzmán J, Macías-Rubalcava ML, Orozco S, Anaya AL, Orozco-Segovia A (2015). Complex dormancy in the seeds of Hypericum philonotis. Functional Ecology of Plants 213:32-39.

Shekhawat MS, Manokari M (2016). Impact of auxins on vegetative propagation through stem cuttings of Couroupita guianensis Aubl.: A conservation approach. Scientifica 2016, Article ID 6587571.

Thetford M, Miller D (2002). Propagation of 4 Florida coastal dune species. Native Plants Journal3(2):112-120.

Thompson K, Jalili A, Hodgson JG, Hamzeh'ee B, Asri Y, Shaw S, ... Safavi $\mathrm{R}$ (2001). Seed size, shape and persistence in the soil in an Iranian flora. Seed Science Research 11:345-355.

Trovato A, Raneri E, Kouladis M, Tzakou O, Taviano MF, Galati EM (2001). Anti-inflammatory and analgesic activity of Hypericum empetrifolium Willd.(Guttiferae).II Farmaco 56(5-7):455-457.

Uniyal RC, Prasad P, Nautiyal AR (1993). Vegetative propagation in Dalbergia sericea: Influence of growth hormones on rooting behaviour of stem cuttings. Journal of Tropical Forest Science 6:21-25.

Veierskov B, Andersen AS, Erikson EN (1982). Dynamics of extractable carbohydrate in Pisum sativum: I. Carbohydrate and nitrogen content in pea plants and cuttings grown at two different irradiances. Physiologia Plantarum 55:167-173. 